\title{
Locking Dorsal Plate in Four-Bone Arthrodesis in SLAC and SNAC 3 Wrist
}

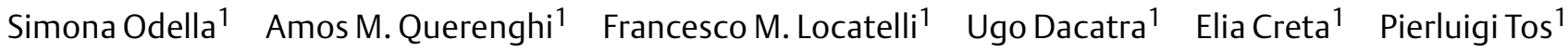 \\ ${ }^{1}$ Operative Unit of Microsurgery and Hand Surgery, Ospedale \\ Gaetano Pini-CTO, Milan, Italy \\ Address for correspondence Simona Odella, MD, Operative Unit of \\ Microsurgery and Hand Surgery, Ospedale Gaetano Pini-CTO, Milan, \\ Italy (e-mail: simonettaodella@gmail.com).
} Joints 2018;6:37-41.

\begin{abstract}
Keywords

- four-bone arthrodesis

- SLAC

- SNAC

- wrist

- locking plate

Purpose The aim of this study was to evaluate the effectiveness and the safety of performing a four-bone arthrodesis (FBA) with dorsal locking plate in patients suffering from stage III scapholunate advanced collapse/scaphoid nonunion advance collapse (SLAC/SNAC) wrist.

Methods We evaluated retrospectively 20 patients surgically treated by a FA with the use of locking dorsal plate. All the patients were clinically evaluated at follow-up for grip strength, range of motion, and pain (visual analog scale), and with the Disability of the Arm, Shoulder and Hand score and the Mayo wrist score. Imaging evaluation was performed on standard X-rays.

Results The mean follow-up was 6 years (range: 1-11 years). During follow-up, the patients showed good clinical outcomes in terms of pain relief and grip strength. Revision surgery was necessary only in one case because of screws loosening. In all cases, a solid bone fusion was achieved except in one patient, who presented a healing of lunocapitate joint. This condition did not affect the clinical outcomes.

Conclusion FBA performed using a dorsal locking plate is a salvage procedure effective in treating stage III SLAC/SNAC wrist. In our study, this technique provided good clinical outcomes at mid-term follow-up with a very low complication rate. Level of Evidence Level IV, therapeutic case series.
\end{abstract}

\section{Introduction}

Scapholunate (SL) ligament integrity is crucial in maintaining the stability of the wrist. In fact, a lesion of this ligament could also lead to a degenerative change called scapholunate advanced collapse (SLAC) with a severe articular impairment.

The SLAC condition was first described in 1984 by Watson and Ballet, ${ }^{1}$ who described an initial SL incompetence with an initial degenerative condition of the radioscaphoid joint (stage I), followed by a more important degeneration of it (stage II) with a progressive involvement to the midcarpal joint (stage III). After these three stages, a stage IV was introduced to indicate a condition with a pan-radiocarpal osteoarthritis $(\mathrm{OA})^{2}$ (-Fig. 1). received

July 2, 2017

accepted after revision

published online

February 12, 2018
January 2, 2018
A similar progressive wrist degeneration is due to a scaphoid nonunion in undiagnosed fracture. The same progressive degenerative stages are described and the same surgical treatment is indicated in case of scaphoid nonunion advanced collapse (SNAC).

The treatment of all these conditions is surgical since no conservative treatment can restore both the competency of the SL ligament and the degenerated cartilage surfaces.

In advanced stages (stage III), the treatment is represented mostly by two salvage procedure: proximal row carpectomy (PRC) or scaphoid excision with fusion of the lunate, triquetrum, hamate and capitate, so-called four-bone arthrodesis (FBA).

The aim of this study is to evaluate the clinical and radiological outcomes in patients who underwent a FBA with dorsal locking plate because of a stage III SLAC/SNAC.

Copyright $\odot 2018$ Georg Thieme Verlag License terms KG Stuttgart · New York
DOI https://doi.org/

10.1055/s-0038-1626738. ISSN 2282-4324. 

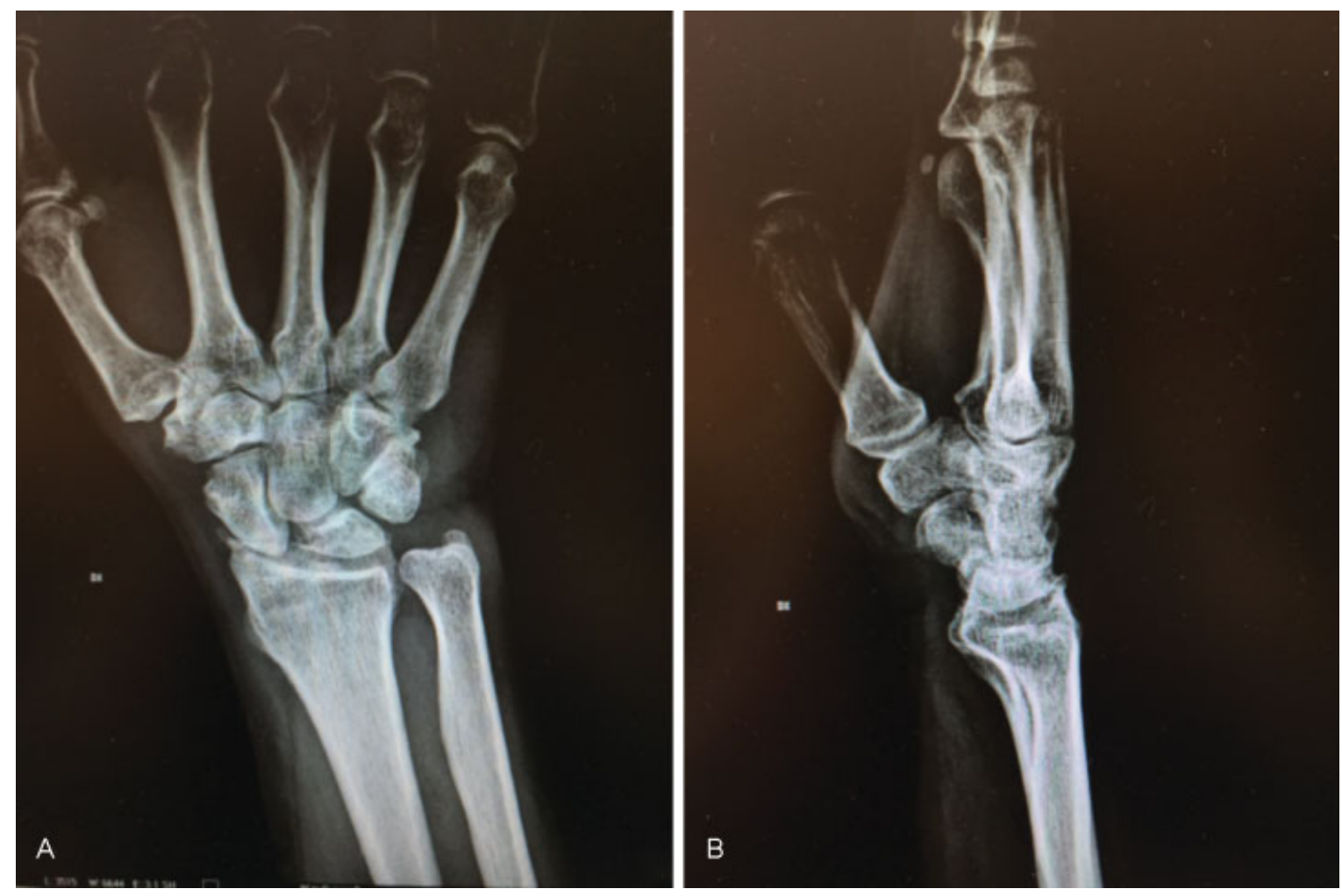

Fig. 1 Stage III scapholunate advanced collapse wrist. Anteroposterior (A) and lateral views (B) show damage to the radioscaphoid and lunocapitate articular surfaces.

\section{Methods}

The inclusion criteria of this retrospective study were: stage III SLAC/SNAC wrist, surgical treatment performed between 2005 and 2010, and use of a locking dorsal plate (LDP) in performing the FBA. The diagnosis of SLAC/SNAC wrist was performed on the evaluation of standard X-rays.

Twenty patients ( 18 males and 2 females) were enrolled in this study. The mean age of the patients was 53.1 years. Fourteen patients were affected by a stage III SNAC and six by a stage III SLAC. No previous surgery to the affected wrist had been performed in 18 patients, one patient had open reduction and internal fixation with staple in scaphoid fracture, and one had proximal scaphoid pole excision and prosthesis substitution. In 14 cases, surgery was performed on the dominant upper arm, while in 6 cases the nondominant side was involved.

Surgery was performed through a dorsal approach to the carpus: a longitudinal midcarpal skin incision was performed, then the third extensor retinaculum was opened with retraction of the extensor pollicis longus. Triangular capsulotomy was achieved following the fiber of the radiotriquetral and dorsal intercarpal ligaments, then a scaphoidectomy was performed and the whole cartilage surfaces between capitate, hamate, triquetrum, and lunate were removed. All the four bones were temporarily fixed with Kwires, paying attention to place in neutral position the lunate, thus reducing the risk of dorsal intercalated segment instability and maintaining the carpal height, and then the locking plate was placed. When all the screws were positioned, the K-wires were removed. After removal of the cartilage surface, cancellous bone from the scaphoid was used to fill all the gaps to promote fusion. Attention was paid to mill the carpal bones, in particular the lunate that is more sclerotic than other carpal bones, to allow the plate to be placed under the dorsal margin of the bones, thus avoiding dorsal impingement with radial edge during wrist extension.

Three different type of dorsal locking plate were used: Arthrodesis Plate 2.0 (Medartis, Basel, Switzerland) in 5 patients, Hub-Cap TM (Acumed, Hillsboro, Oregon, United States) in 10 patients, and Flower plate (KLS Martin, Freiburg, Germany) in 5 patients.

After surgery, all patients wore an immobilization cast for 6 weeks. Rehabilitation was allowed only when healing was confirmed on X-rays and after positive clinical check.

All patients were clinically and radiographically re-evaluated at the final follow-up. The clinical outcomes were assessed by the evaluation of pain (visual analog scale, VAS score), range of motion (ROM) (flexion and extension of the wrist) and grip strength, and by collecting the Mayo wrist score and the Disability of the Arm, Shoulder and Hand (DASH) score, while the imaging evaluation was based on standard X-rays of the wrist (anteroposterior and lateral views).

\section{Results}

The mean follow-up was 6 years (range: $1-11$ years). The mean DASH score was $16.6 \pm 11$ points; the Mayo wrist 
score was good for 2 patients, fair for 16 patients, and bad for 2 patients. In the latter cases, surgery decreased the ROM of the wrist due to the dorsal prominence of the plate. VAS was two in case of heavy activity. The mean grip strength was $75 \%$ compared with the healthy side.

No differences were noticed using different kinds of locking dorsal plate. No ulnar translation of the carpal bone was detected in this series.

The mean ROM in flexion was $42^{\circ} \pm 18.5^{\circ}$ (range: $20-70^{\circ}$ ) and in extension was $37^{\circ} \pm 12.7^{\circ}$ (range: $20-60^{\circ}$ ) (-Table 1 ).

In one case, a revision surgery was needed to remove the device because of the loosening of the screws. In this case, a solid fusion between lunate and capitate was achieved and no further surgery was necessary (-Fig. 2).

\section{Discussion}

The SL ligament, as the scaphoid, has a key role in maintaining a normal kinematics of the wrist and in making possible a full ROM without pain. When this ligament is torn, it should be reconstructed to avoid degenerative changes to midcarpal articular surfaces. Similar degenerative changes can occur in case of unrecognized scaphoid nonunion.

Several techniques were presented to reconstruct this ligament $\mathrm{t}^{3-5}$ and to promote healing of scaphoid nonunion, and all of them could reach good clinical outcomes if both

Table 1 Descriptive statistics and follow-up data

\begin{tabular}{|l|l|l|l|l|l|}
\hline & $\mathrm{M} / \mathrm{F}$ & Age & $\begin{array}{l}\text { Involved } \\
\text { wrist } \\
\text { (R dominant) }\end{array}$ & Extension & Flexion \\
\hline Patient 1 & $\mathrm{M}$ & 58 & $\mathrm{R} / \mathrm{L}$ & 60 & 40 \\
\hline Patient 2 & $\mathrm{M}$ & 57 & $\mathrm{R} / \mathrm{R}$ & 40 & 70 \\
\hline Patient 3 & $\mathrm{F}$ & 73 & $\mathrm{R} / \mathrm{R}$ & 30 & 20 \\
\hline Patient 4 & $\mathrm{M}$ & 59 & $\mathrm{R} / \mathrm{R}$ & 55 & 60 \\
\hline Patient 5 & $\mathrm{M}$ & 64 & $\mathrm{R} / \mathrm{R}$ & 20 & 30 \\
\hline Patient 6 & $\mathrm{M}$ & 67 & $\mathrm{R} / \mathrm{L}$ & 40 & 70 \\
\hline Patient 7 & $\mathrm{M}$ & 62 & $\mathrm{R} / \mathrm{L}$ & 20 & 20 \\
\hline Patient 8 & $\mathrm{M}$ & 57 & $\mathrm{R} / \mathrm{R}$ & 30 & 60 \\
\hline Patient 9 & $\mathrm{M}$ & 24 & $\mathrm{R} / \mathrm{L}$ & 40 & 50 \\
\hline Patient 10 & $\mathrm{M}$ & 49 & $\mathrm{R} / \mathrm{L}$ & 20 & 20 \\
\hline Patient 11 & $\mathrm{M}$ & 55 & $\mathrm{R} / \mathrm{L}$ & 50 & 20 \\
\hline Patient 12 & $\mathrm{M}$ & 88 & $\mathrm{R} / \mathrm{R}$ & 30 & 50 \\
\hline Patient 13 & $\mathrm{M}$ & 49 & $\mathrm{R} / \mathrm{R}$ & 40 & 20 \\
\hline Patient 14 & $\mathrm{M}$ & 65 & $\mathrm{R} / \mathrm{R}$ & 30 & 30 \\
\hline Patient 15 & $\mathrm{M}$ & 60 & $\mathrm{R} / \mathrm{R}$ & 60 & 60 \\
\hline Patient 16 & $\mathrm{M}$ & 38 & $\mathrm{R} / \mathrm{R}$ & 40 & 30 \\
\hline Patient 17 & $\mathrm{M}$ & 46 & $\mathrm{R} / \mathrm{R}$ & 30 & 70 \\
\hline Patient 18 & $\mathrm{M}$ & 30 & $\mathrm{R} / \mathrm{R}$ & 30 & 50 \\
\hline Patient 19 & $\mathrm{F}$ & 60 & $\mathrm{R} / \mathrm{R}$ & $\mathrm{M}$ & 30 \\
\hline Patient 20 & $\mathrm{M}$ & 53 & $\mathrm{R} / \mathrm{R}$ & $\mathrm{M}$ & $\mathrm{3}$ \\
\hline & $\mathrm{M} / 2 \mathrm{~F}$ & 53.1 & $\mathrm{dominant}$ & $\mathrm{3}$ & \\
\hline
\end{tabular}

radiocarpal and midcarpal articular surfaces are preserved (stage I and II). If degenerative changes in articular surfaces take places in a wrist suffering from SL dissociation, SLAC, or from SNAC, wrist could develop radioscaphoid and midcarpal OA. These pathological conditions are classified in four stages (from I to IV), and in stage III (radioscaphoid and capitolunate $\mathrm{OA}$, preserved radiolunate articular surface) the surgical salvage treatments are represented by PRC and FBA. Several studies compared the two techniques, ${ }^{6-11}$ highlighting their advantages and disadvantages.

PRC restores a greater ROM and there is no need of implant or bone fusion, but it can preserve less grip strength compared with FBA. $^{7}$ However, FBA, which maintains a normal carpal height, can assure more preservation of grip strength, but guarantees less ROM and has higher rate of complications, such as implant failure or carpal nonunion.

In FBA, several technique were presented in the literature using different implant such as using K-wire, Herbert's screws, staples, or specific plates. Multiple pinning was initially used, then staples were introduced in 1990s and different designs were studied in 2000s. Dorsal circular plates with locking design were recently presented. The goal was to provide stable fixation and early mobilization, thus improving final ROM.

The use of specific plate, as shown in studies by Kendall et $\mathrm{al}^{12}$ and Merrell et al, ${ }^{13}$ showed good results in the shortand mid-term follow-up, with a low rate of complications, particularly nonunion of the carpal bones.

Several studies compared different hardware designs to understand if there is a real advantage in using LDP. Literature referred about a low nonunion rate in case of K-wire technique, ranging from $3 \%$ to $16 \% ;^{1-7}$ in contrast, migration, entry-point infection, and new surgery to remove K-wire were more or less systematically reported, with discomfort for the patients. ${ }^{14}$ Even with staples or compression screws the nonunion rate was similar, and time of immobilization after surgery was 6 to 10 weeks. In case of staples, removal was required because of dorsal impingement. $^{15}$

Nonlocking dorsal plates (NLDPs) were introduced to obtain greater stability and to allow early mobilization and to gain greater ROM, but results were less satisfactory than expected. De Smet et $\mathrm{al}^{6}$ reported approximately $62.5 \%$ of nonunion and no improvement in ROM. Merrell et $\mathrm{al}^{13}$ observed that this high rate of nonunion is partly due to the use of plate to compensate for imprecision in performing surgical technique. It is necessary a high precision in reaming into cancellous bone, grafting from ipsilateral radius or excised scaphoid, elimination of riming debris, correct position of the plate to avoid dorsal impingement and fixation of each carpal bone by two screws. They also recommended 6 weeks of immobilization.

Kraisarin et $\mathrm{al}^{16}$ in a cadaveric study compared NLDPs, Kwires, and LDPs. They demonstrated the biomechanical superiority of LDP. Rhee and Shyn ${ }^{17}$ reported approximately $4 \%$ of nonunion rate after 6 weeks of immobilization. On the contrary, Luegmair and Houvet ${ }^{18}$ reported $8 \%$ and $9 \%$ nonunion with 1 to 2 weeks of strict immobilization followed by 

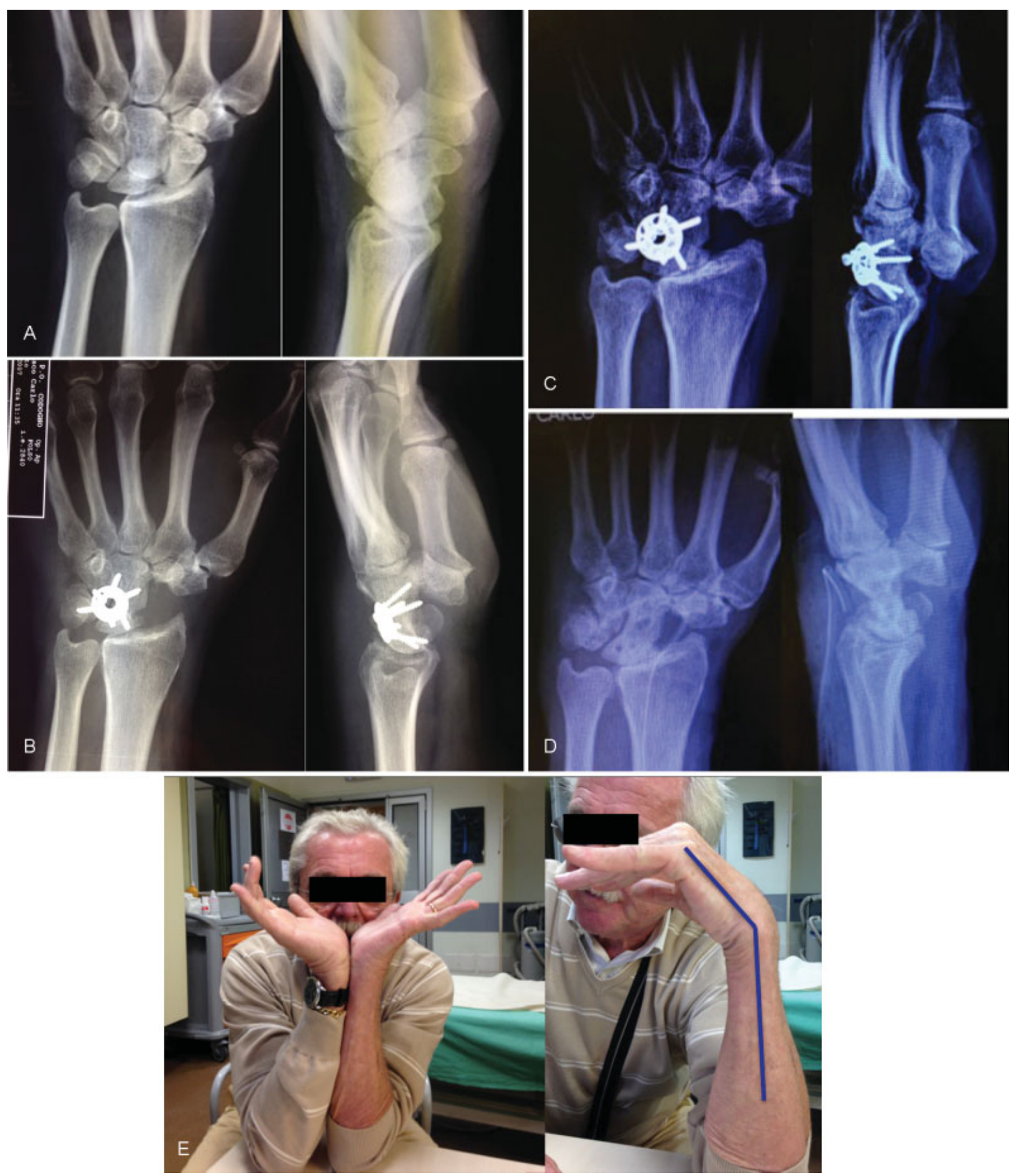

Fig. 2 Stage III scaphoid nonunion advance collapse wrist. (A) Anteroposterior and lateral view. (B) Surgical treatment with dorsal locking plate. (C) Screws loosening 9 years after surgery. (D) Plate and screws removal: lunocapitate joint fusion is evident. (E) Clinical outcome 2 months after hardware removal.

a removable cast or 2 more weeks and rehabilitation after 4 weeks.

In opposite of what expected, using DLP does not give advantages in term of ROM, strength, or pain after surgery if compared with staples. The real improvement is in time to return to work. Pauchard et $\mathrm{al}^{14}$ showed that return to work was 3 to 4 months before with DLP than with staples or NLDP; ${ }^{14}$ even the rate to return to work was higher in LDP.

Ritt et al and Cayci and Carlsen showed that the block effect of the four-corner procedure and the biomechanical effectiveness of this surgery were achieved even if the lunotriquetral joint did not fuse. ${ }^{19,20}$ Nevertheless, the goal 
of four-corner procedure is to fuse the four joint lines and it is necessary for a meticulous cartilage resection to obtain a complete arthrodesis.

The main reason for revision surgery is dorsal impingement between the fixation device and the posterior edge of radius. However, Le Corre et $\mathrm{al}^{21}$ observed no correlation between hardware failure and surgical revision in the plate group, as $44 \%$ of failed implant were asymptomatic.

The duration of postoperative immobilization is still controversial in the literature. Some authors suggest that stable fixation allows early rehabilitation; ${ }^{22}$ however, others recommended 6 to 8 weeks of cast after surgery to obtain a complete healing. ${ }^{23}$ Tielemans et $\mathrm{al}^{24}$ established that a shorter postoperative immobilization results in better recovery of function.

In our series, the use of these plates showed good clinical results, with a DASH score that could be compared with the score of the healthy population, ${ }^{25}$ with a very low rate of surgical revision and complications.

As stated in several clinical studies and confirmed also in biomechanical studies, the FBA needs a good reduction in the lunate before the arthrodesis ${ }^{14,15,26}$ to improve ROM. Indeed, in all of our cases, the first surgical step was to get a good reduction in the lunate before performing the fusion. The use of bone chips from the excised scaphoid was preferred to avoid harvest site morbidity and to shorten the operative time. Furthermore, we played great attention in reaming cartilage, sinking the plate, and maintaining the height of carpal bones.

In conclusion, the use of dorsal plate in performing FBA seems to be a safe and effective procedure with a low rate of complications and good clinical and imaging outcome at mid-term follow-up in treating stage III SLAC/SNAC wrist.

\section{References}

1 Watson HK, Ballet FL. The SLAC wrist: scapholunate advanced collapse pattern of degenerative arthritis. J Hand Surg Am 1984;9 (03):358-365

2 Weiss KE, Rodner CM. Osteoarthritis of the wrist. J Hand Surg Am 2007;32(05):725-746

3 Linscheid RL, Dobyns JH. Treatment of scapholunate dissociation. Rotatory subluxation of the scaphoid. Hand Clin 1992;8(04): 645-652

4 Garcia-Elias M, Lluch AL, Stanley JK. Three-ligament tenodesis for the treatment of scapholunate dissociation: indications and surgical technique. J Hand Surg Am 2006;31(01):125-134

5 Brunelli GA, Brunelli GA. [Carpal instability with scapho-lunate dissociation treated using the flexor carpi radialis and scaphoidtrapezoid ligament repair: foundations, technique and results of preliminary series]. Rev Chir Orthop Repar Appar Mot 2003;89 (02):152-157

6 De Smet L, Deprez P, Duerinckx J, Degreef I. Outcome of fourcorner arthrodesis for advanced carpal collapse: circular plate versus traditional techniques. Acta Orthop Belg 2009;75(03): 323-327

7 Cohen MS, Kozin SH. Degenerative arthritis of the wrist: proximal row carpectomy versus scaphoid excision and four-corner arthrodesis. J Hand Surg Am 2001;26(01):94-104

8 Vanhove W, De Vil J, Van Seymortier P, Boone B, Verdonk R. Proximal row carpectomy versus four-corner arthrodesis as a treatment for SLAC (scapholunate advanced collapse) wrist. J Hand Surg Eur Vol 2008;33(02):118-125

9 Dacho AK, Baumeister S, Germann G, Sauerbier M. Comparison of proximal row carpectomy and midcarpal arthrodesis for the treatment of scaphoid nonunion advanced collapse (SNAC-wrist) and scapholunate advanced collapse (SLAC-wrist) in stage II. J Plast Reconstr Aesthet Surg 2008;61(10):1210-1218

10 Mulford JS, Ceulemans LJ, Nam D, Axelrod TS. Proximal row carpectomy vs four corner fusion for scapholunate (Slac) or scaphoid nonunion advanced collapse (Snac) wrists: a systematic review of outcomes. J Hand Surg Eur Vol 2009;34(02):256-263

11 Kiefhaber TR. Management of scapholunate advanced collapse pattern of degenerative arthritis of the wrist. J Hand Surg Am 2009;34(08):1527-1530

12 Kendall CB, Brown TR, Millon SJ, Rudisill LE Jr, Sanders JL, Tanner SL. Results of four-corner arthrodesis using dorsal circular plate fixation. J Hand Surg Am 2005;30(05):903-907

13 Merrell GA, McDermott EM, Weiss AP. Four-corner arthrodesis using a circular plate and distal radius bone grafting: a consecutive case series. J Hand Surg Am 2008;33(05):635-642

14 Pauchard N, Lecoanet-Strugarek C, Segret J, De Gasperi M, Dap F, Dautel G. Dorsal locking plates versus staples in four-corner fusion: a comparative clinical and radiological study. Orthop Traumatol Surg Res 2014;100(06):593-597

15 De Carli P, Donndorff AG, Alfie VA, Boretto JG, López Ovenza JM, Gallucci GL. Four-corner arthrodesis: influence of the position of the lunate on postoperative wrist motion: a cadaveric study. J Hand Surg Am 2007;32(09):1356-1362

16 Kraisarin J, Dennison DG, Berglund LJ, An KN, Shin AY. Biomechanical comparison of three fixation techniques used for four-corner arthrodesis. J Hand Surg Eur Vol 2011;36(07):560-567

17 Rhee PC, Shin AY. The rate of successful four-corner arthrodesis with a locking, dorsal circular polyether-ether-ketone (PEEKOptima) plate. J Hand Surg Eur Vol 2013;38(07):767-773

18 Luegmair M, Houvet P. Effectiveness of four-corner arthrodesis with use of a locked dorsal circular plate. Clin Orthop Relat Res 2012;470(10):2764-2770

19 Ritt MJ, Bishop AT, Berger RA, Linscheid RL, Berglund LJ, An KN. Lunotriquetral ligament properties: a comparison of three anatomic subregions. J Hand Surg Am 1998;23(03):425-431

20 Cayci C, Carlsen BT. Osteoarthritis of the wrist. Plast Reconstr Surg 2014;133(03):605-615

21 Le Corre A, Ardouin L, Loubersac T, Gaisne E, Bellemère P. Retrospective study of two fixation methods for 4-corner fusion: Shape-memory staple vs. dorsal circular plate. Chir Main 2015; 34(06):300-306

22 Espinoza DP, Schertenleib P. Four-corner bone arthrodesis with dorsal rectangular plate: series and personal technique. J Hand Surg Eur Vol 2009;34(05):609-613

23 Sauerbier M, Tränkle M, Linsner G, Bickert B, Germann G. Midcarpal arthrodesis with complete scaphoid excision and interposition bone graft in the treatment of advanced carpal collapse (SNAC/SLAC wrist): operative technique and outcome assessment. J Hand Surg [Br] 2000;25(04):341-345

24 Tielemans A, Van Innis F, Troussel S, Detrembleur C, Libouton X, Lequint $\mathrm{T}$. Effect of four-corner fusion with locking plate without bone graft on functional recovery of the wrist: new treatment guidelines. Hand Surg Rehabil 2017;36(03):186-191

25 Hunsaker FG, Cioffi DA, Amadio PC, Wright JG, Caughlin B. The American Academy of Orthopaedic Surgeons outcomes instruments: normative values from the general population. J Bone Joint Surg Am 2002;84-A(02):208-215

26 Wyrick JD, Stern PJ, Kiefhaber TR. Motion-preserving procedures in the treatment of scapholunate advanced collapse wrist: proximal row carpectomy versus four-corner arthrodesis. J Hand Surg Am 1995;20(06):965-970 